\title{
A Comparison of the Efficacy of Non-alcoholic $0.05 \%$ Cetylpyridinium Mouthwash and Chlorhexidine Alcohol-free Mouth Rinse on Patients with Gingivitis: A Double-blind Randomized Controlled Trial
}

\author{
Amirhossein Farahmand ${ }^{1}$, Ferena Sayar ${ }^{2}$, Majid Habibi ${ }^{3}$, Mahsa Soleimani ${ }^{1}$, Nazilla Naghizadeh ${ }^{4}$, Bahareh \\ Jafarzadeh Esfahani ${ }^{3}$
}

${ }^{1}$ Assistant Professor, Department of Periodontics, Faculty of Dentistry, Tehran Medical Sciences, Islamic Azad University, Tehran, Iran

${ }^{2}$ Associate Professor, Department of Periodontics, Faculty of Dentistry, Tehran Medical Sciences, Islamic Azad

University, Tehran, Iran

${ }^{3}$ Dentist (Private Practice), Tehran, Iran

${ }^{4}$ Periodontist (Private Practice), Tehran, Iran

Type of article: Original

\begin{abstract}
Background: Oral health preservation is of major importance in patients undergoing periodontal surgery. Tooth brushing is a competency that is challenging to perform. Therefore, materials with biochemical properties that can control the tooth plaque biofilm are used.

Objective: The purpose of the study was to determine the clinical outcome of alcohol-free Chlorhexidine (AFCHX) $0.12 \%$ oral rinse in comparison with $0.05 \%$ Cetylpyridinium chloride (CPC) non-alcoholic mouthwash in outpatients with periodontitis.

Methods: Patients with periodontal diseases attending the Department of Periodontology, Dental School of the Islamic Azad University of Medical Sciences, Tehran, Iran received a double-blind randomized controlled trial. In this study, a total of 38 patients with gingivitis and pocket depth $\leq 4 \mathrm{~mm}$ were randomly allocated into two equal study groups and followed up within 90 days: Group A (performed mouth rising twice a day with the liquid including $10 \mathrm{ml}$ of the $0.05 \% \mathrm{CPC}$ without ethanol), Group B (performed mouth rising twice daily with $10 \mathrm{ml}$ of the alcohol-free $0.012 \%$ chlorhexidine solution). Furthermore, periodontal parameters and Stain Index (SI) were obtained at baseline and for both groups one month later. ANOVA was used to analyze the data. Statistical significance was defined as $\mathrm{p}$-value $<0.05$.

Results: Full-mouth plaque index (PI) was non-significantly different in the two groups, and the decline was $35 \%$ for the CPC group and 44\% for the individual AFCHX group. Moreover, reductions in BOP were statistically significant for the CHX group after the $12^{\text {th }}$ week $(\mathrm{p}=0.0001)$. Additionally, the PD drop within 30 days was statistically significant $(1.92 \pm 0.30)$ AFCHX group and $(2.30 \pm 0.36) \mathrm{CPC}$ group $(\mathrm{p}=0.002)$. Meanwhile, CPC and AFCHX plan of teeth were also compared, and greater rates of staining were observed in AFCHX areas of teeth at days 7 to four weeks.

Conclusion: The findings indicated that the application of a therapeutic CPC mouth rinse, twice daily aids control plaque as well as gingivitis, and periodontitis surpassing traditional plaque control, although not as much as AFCHX mouthwash.

Trial registration: The study was registered under Identifier No. NCT02756377 at ClinicalTrials.gov.

Funding: This study was entirely sponsored by researchers and did not receive a specific grant from any funding agency.

Keywords: Cetylpyridinium, Chlorhexidine, Periodontal Disease
\end{abstract}

\section{Corresponding author:}

Associate Professor Dr. Ferena Sayar, Department of Periodontics, Faculty of Dentistry, Tehran Medical Sciences, Islamic Azad University, Tehran, Iran. Tel: +98.9121059378, E-mail: sayar_f@yahoo.com

Received: January 18, 2019, Accepted: October 21, 2020, Published: June 2021

This article has been reviewed / commented by three experts

Ethics approval: Ethical Commission of Faculty of Dentistry, Tehran Medical Sciences, Islamic Azad University, Tehran, Iran (Ref: 24623).

(C) 2021 The Authors. This is an open access article under the terms of the Creative Commons Attribution-NonCommercialNoDerivs License, which permits use and distribution in any medium, provided the original work is properly cited, the use is non-commercial and no modifications or adaptations are made. 
Note: This study has followed the CONSORT Statement, which is an evidence-based, minimum set of recommendations for reporting randomized trials. It offers a standard way for authors to prepare reports of trial findings, facilitating their complete and transparent reporting, and aiding their critical appraisal and interpretation.

\author{
Abbreviations / Acronyms: \\ AFCHX: Alcohol-free Chlorhexidine; CHX: Chlorhexidine; CPC: Cetylpyridinium chloride
}

\title{
1. Introduction
}

Dental plaque plays a major role in the progress of gingivitis, which in turn can develop into periodontitis (1). Periodontal diseases occur when pathogenic microbial tooth plaque acts on a suspected host (2). Additionally, traditional removal of bacterial dental plaque is the most effective technique to control such conditions as tooth caries, gingivitis, and for the prevention of rising periodontal disease $(3,4)$. However, daily brushing has been reported to eliminate plaque deposits only partially (5); the large preponderance of gingivitis means that the conventional self-performing plaque is inadequate; the resistor restricts gingival inflammation (6). Subjects' attempts, nevertheless, are frequently jeopardized by the appearance of hard-to-reach regions as well as an insufficient proficiency, little stimulus, and lack of admission. As a result, the application of antimicrobial mouthwash in conjunction with the usual oral health regimens has been a factor for intensifying plaque removal ( 7 , 8). The adjunct usage of anti-microbial factors can benefit the adjunct control of supra-gingival biofilm. Many antimicrobials have been examined as adjuncts to conventional tooth plaque biofilm control to improve the results achieved in oral home-care (6). To this end, there is a type of mouthwash, of which Chlorhexidine (CHX) has been presented as the routine efficient chemical factor to regulate dental plaque (9-11). The high potency of CHX, a cationic bisbiguanide molecule, has been ascribed to its high substantively in the mouth, as well as its bactericidal and bacteriostatic operations (12). In addition, $\mathrm{CHX}$ is regarded as the gold standard material in regulating oral biofilm development in the mouth or microbial pathogens change by mouth-aerosols (13-18), which is a reason for its widespread antibacterial spectrum $(17,19)$. As an adjunct to conservative oral hygiene systems, the benefit of antimicrobial mouth rinses is regarded a complement to improve plaque control (20-23). Particularly, CPC, which carries prolonged records of safe and proficient intra-oral utilization has commonly been applied as an antibacterial component to improve clinical efficacy $(24,25)$. CPC, which is a cationic quaternary ammonium mixture, has been offered as an option to CHX. CPC is a useful yield for regulative dental plaque biofilm development. It declines the bacterial plaque on the tooth surface that produces periodontitis, and thus inhibits the inflammation of the gums, as well as bad breath. Although it is marginally more effective than CHX at reducing dental plaque biofilm formation, it is distinguished by the appearance of significantly more uncommon adverse effects, such as tooth staining or color change. It is caused by CHX mouthwash. The anti-plaque effect of CPC can be attributed to the cationic component of CPC, which simply binds to the negatively charged proteins of the oral tissue (26-28). Quirynen et al., on the other hand, described the possibility of a unique $0.12 \% \mathrm{CHX}+0.05 \% \mathrm{CPC}$ non-alcoholic formulation as an effective anti-dental plaque cause for long-range control with diminished individuals' side effects (29). The present study evaluated the anti-plaque impacts of the $0.05 \% \mathrm{CPC}$ non-alcoholic formulation as an effective anti-plaque compared to $0.12 \%$ CHX. In both groups, periodontal parameters and extrinsic tooth staining were assessed.

\section{Material and Methods}

\subsection{Research design and contributors}

This double-blind randomized clinical trial was conducted from December 2014 to May 2015. It was implemented on 38 subjects admitted to the Department of Periodontology, Dental Faculty of the Islamic Azad University of Medical Sciences, Tehran, Iran.

\subsection{Selection Criteria}

The inclusion criteria were as follows:

1) Patients with gingivitis;

2) Age $>18$ years old;

3) Having at least 20 teeth

The exclusion criteria were:

1) Patients with a history of systemic illness;

2) Patients with no orthodontic devices or removable prostheses (to avoid food particles and plaque that can accumulate on the appliance, this will help prevent plaque build-up);

3) Patients with a known allergy to any of the components of mouthwashes;

4) Patients who had taken antibiotics or anti-inflammatory medication for the last 3 months; 
5) Patients with cavitated caries lesions;

6) Pregnant or breastfeeding women ;

7) Smokers;

8) Patients under periodontal therapy through for the last six months.

\subsection{Intervention and measurements}

On the first visit, all participants received scaling and root planning, as well as proficient prevention and inhibition; oral hygiene instructions, including double-daily brushing, were delivered. The contributors cleaned their teeth for at least two minutes using the Bass brushing method, and these patients were randomly and evenly divided into two groups: Group A: rinsed their mouths twice a day with a suspension containing $10 \mathrm{ml}$ of 0.05 CPC (VI-one, Rojin, Cosmetic-Lab, Kurdistan-Iran), Group B: performed twice daily mouth-rinse with $10 \mathrm{ml}$ of the $0.012 \%$ AFCHX (Kim Laboratories, Spain). Patients in both groups were assigned a container at random to rinse the objects with mouthwash for 60 seconds once in ante meridian and at nighttime following tooth cleaning or brushing their teeth. It was advised to the subjects to abstain from eating or drinking for half an hour after using the mouthwash.

\subsection{Outcomes}

Split-mouth is justified, and the study results are more perfect. Intersecting tests for therapeutic procedures or rapidly changing conditions may be unfeasible and immoral. A parallel-team and a split-mouth randomized, doubleblind, controlled trial were used in the study, and all periodontal parameters were gathered by a blinded experiment. Following that, weekly follow-ups were performed for four weeks. Individuals returned every week for a four-week interval study. Plaque index (Plaque index was scored according to Turesky's (30) and O'Leary's index) (31) and probing depth (PD) were placed with slight force probing into the gingival crevice/sulcus by a periodontal probe. Within 30 seconds of probing, the bleeding index (BI) was recorded as present or absent at six sites per tooth (Score 0 : No bleeding following probing. Score 1: A single separate bleeding point visible after probing) scores $(32,33)$, and Stain index (SI using scores on the Lobene Stain Index; scored 0-3. Where $0=$ no stain, $1=$ light stain, $2=$ moderate stain and 3 = heavy stain) (34).

\subsection{Sample size}

According to prior research, the sample size was calculated by detecting differences in the primary result of periodontal disease measurements probing pocket depth (PD) from the first day to the last day of follow-up. The sample size for the study was determined using the MINITAB's "two-sample t-test sample size calculation" tab, with $\alpha=0.05, \beta=0.05$ mean a deviation of equal to 1.65 and merged standard variation $=1.4$. Therefore, each group required at least 17 cases.

\subsection{Randomization and Blinding}

A single investigator prepared the randomization, who had no role in the treatment of contributors. Qualified participants who affirmed their continuing dedication to the investigation were block-randomized for qualified participants who confirmed their continued commitment to the experiment were block-randomized for operation in a double-blind manner; block randomization with a 4:1 allocation was used. Total mouthwashes were fitted in the same glass bottles, which were labeled with (A, B). Each participant selected one symbol from a box, which determined his/her subsequence of the mouthwash use. The order of mouthwash use was randomized, and the entire clinical research was supervised by a calibrated inspector; also, prior to opening the trial, one examiner (a periodontist) was trained to the calibration manner twice to minimize the examiner's reliability. The examiners had been calibrated for one week prior to the start of the experiments, and the periodontal assessment was carried out by a single calibrated examiner. An investigator evaluated the subjects twice, once at 0 and once for two days. The calibration was confirmed because $90 \%$ of the studies were recorded within the $1.0 \mathrm{~mm}$ range.

\subsection{Statistical analysis}

Data were analyzed by IBMC SPSS $\odot$ Statistics 21 (IBMC Corp., Armonk, NY, USA). ANCOVA test was used to control potential distortion variables. Furthermore, a t-test was used for the paired sample's within-group association, while the judgment of variation (ANOVA) was used for the within-group comparison, using the average variance valences of the PI, BI, and PD on the first day and one month later. A p-value of $<0.05$ was determined to be statistically significant. 


\subsection{Ethics of research}

Inquiry Ethics Permission and Consent were obtained from the Ethical Commission of Faculty of Dentistry, Tehran Medical Sciences, Islamic Azad University, Tehran, Iran (Ref: 24623). The study was registered under Identifier No. NCT02756377 at ClinicalTrials.gov. All participants were informed both orally and in writing. The contributors provided their consent to participate in the study; also, we were required to keep all of the participants' information private. Oral rinse was made available to subjects on a regular basis and was validated by the Ministry of Health and Medical Education, and was available on the market.

\section{Results}

All 40 cases were tested; none of the cases in either group complained about taste when rising; nevertheless, during the examination, two participants who seemed younger complained about the burning sensation, as well as piercing pain after rinsing with AFCHX. Moreover, Two CPC group participants withdrew from the treatment for reasons unrelated to medication use. Figure 1 depicts the experimental protocol. There were no significant differences in clinical periodontal scores between the CPC and AFCHX groups at the start of the study. In terms of the clinical periodontal index, after 7 days, the outgrowth of periodontal therapy showed a statistically significant decrease in PI, $\mathrm{BI}$, and PD in both groups (Table 1). There was an increase in full-mouth PI in both A and B groups; however, there was a statistically significant variation in full-mouth PI within the two groups. Aside from that, there was no statistically significant difference in full-mouth PI between the two groups at any meeting. This reduction was $35 \%$ for the CPC group and $44 \%$ for the chlorhexidine group (Table 1).

The BI sign did not change in the two groups at the first visit, however there was a statistically significant decline in $\mathrm{BI}$ rates from baseline to 30 days in both groups. At the final visit or $90^{\text {th }}$ day, the decrease in BI mark was greater in group A $(0.150 \pm 12)$ compared to group B $(0.190 .35)(\mathrm{p}=0.0423)$ (Table 1$)$. After the 12 weeks $(\mathrm{p}=0.0001)$, the reduction in BOP was statistically significant for the CHX group. The clinical periodontal parameters revealed that PD did not differ between the groups. There was a statistically significant decrease in PD rates in both groups when compared to the initial visit; While the AFCHX group was compared to each other, the decrease in PD at 90 days was statistically significant $(1.92 \pm 0.30)$ CHX group and (2.30 \pm 0.36$)$ CPC group $(p=0.002)$ (Table 1$)$. At the first visit, the severity of the stain as measured by the discoloration index did not differ between experimental groups. Meanwhile, the CPC and AFCHX tooth plans were compared, and higher rates of staining were seen in AFCHX areas of the teeth at days 7 to 12 weeks (Table 1).

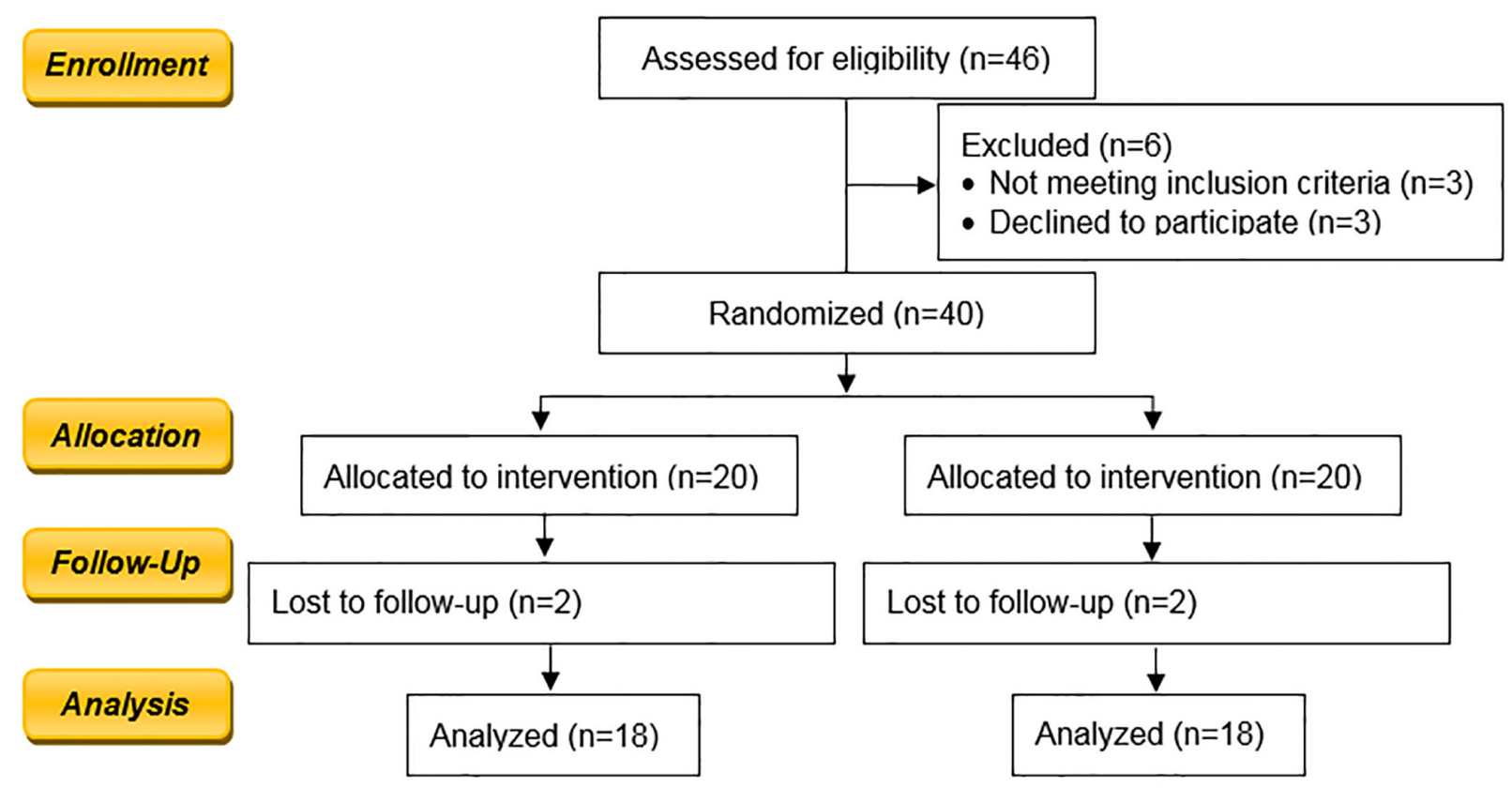

Figure 1. CONSORT 2010 Diagram of the study 
Table 1. Full-mouth $\mathrm{PI}^{*}$ values and $\mathrm{BI}^{*}$ values for all groups at different mouthwash and time; and Change in pocket depth across time and satin index in the study groups

\begin{tabular}{|c|c|c|c|c|c|}
\hline Variables & Group & Baseline & One month & Three months & p-value \\
\hline \multirow[t]{2}{*}{ Plaque index (Tursky) } & $\mathrm{CHX}$ & $2.77 \pm 0.674$ & $1.58 \pm 0.689$ & $0.8 \pm 0.447$ & \multirow[t]{2}{*}{0.986} \\
\hline & $\mathrm{CPC}$ & $2.3 \pm 1.03$ & $1.49 \pm 0.617$ & $0.98 \pm 0.497$ & \\
\hline \multirow[t]{2}{*}{ Plaque index (O'Leary) } & $\mathrm{CHX}$ & $69.70 \pm 17.29$ & $42.76 \pm 9.93$ & $29.06 \pm 7.25$ & \multirow[t]{2}{*}{0.2205} \\
\hline & $\mathrm{CPC}$ & $7388 \pm 1.66$ & $46.23 \pm 9.15$ & $32.25 \pm 7.63$ & \\
\hline \multirow[t]{2}{*}{ Bleeding Index } & $\mathrm{CHX}$ & $0.50 \pm 0.403$ & $0.29 \pm 0.488$ & $0.15 \pm 0.350$ & \multirow[t]{2}{*}{0.0001} \\
\hline & $\mathrm{CPC}$ & $0.43 \pm 0.5$ & $0.26 \pm 0.51$ & $0.15 \pm 0.258$ & \\
\hline \multirow[t]{2}{*}{ Pocket depth } & $\mathrm{CHX}$ & $2.9 \pm 0.820$ & $2.3 \pm 0.54$ & $1.9 \pm 0.301$ & \multirow[t]{2}{*}{0.002} \\
\hline & $\mathrm{CPC}$ & $2.8 \pm 0.719$ & $2.4 \pm 0.50$ & $2.1 \pm 0.352$ & \\
\hline \multirow[t]{2}{*}{ Stain Index } & $\mathrm{CHX}$ & - & $0.47 \pm 0.514$ & $2.54 \pm 0.52$ & \multirow[t]{2}{*}{0.0001} \\
\hline & $\mathrm{CPC}$ & - & $0.62 \pm 0.50$ & $1.56 \pm 0.63$ & \\
\hline
\end{tabular}

\section{Discussion}

The study's main goal was to identify the benefit of the alcohol-free CHX with CPC mouthwash in reducing tooth plaques, alter periodontal tissue healthy, and assess the adverse effects. Loss of hygienic way and inability to attain proper dental brushing can render conventional tooth plaque control ineffective (35). As a result, the usage of mouthwashes may be beneficial in improving plaque biofilm regulation as well as gingiva health by eliminating dental plaque from difficult-to-reach areas. Because of its long-term efficiency in reducing dental plaque, CHX has been recognized as the gold standard among mouthwashes (36). However, it has the problems of creating tooth staining, accumulating alcohol, and altering flavor sensations. These conditions restrict its use primarily to the short term $(37,38)$. Throughout the years, researchers have discussed the lack of side effects of alcohol in mouthwashes for regular use, and some types of research have indicated the intersection between alcohol use in mouthwashes and oral cancer (39). The study focused on two systems of AFCHX and CPC as an adjunctive method to mechanical plaque inhibition. It was explained that there is a significant difference between the AFCHX and CPC for 30 days on PI, BI, and PD indicators and staining symbols. Furthermore, the results showed that the periodontal parameters improved in all groups. Concerning the CHX group, they were more significant than the CPC group. On the 28th day, we discovered that PI in the AFCHX group was lower than CPC. These findings were consistent with previous studies by Quirynen et al., who claimed that CHX $0.12 \%$ and CPC $0.05 \%$ can suffice as an oral rinse. The study's findings indicated the possibility of a recent $\mathrm{CHX} 0.12 \% \mathrm{CPC} 0.05 \%$ non-alcohol aggregate as an effective antidental plaque including an anti-inflammatory factor with diminished unfavorable individuals adverse influences (12, 29). Brownstein et al. demonstrated that $\mathrm{CHX}$ oral-washes, in addition to regular tooth plaque inhibition externally primary limitation, significantly reduced dental plaques, even while the incidence of gingival inflammation persisted permanently after 60 days in participants with moderate-severe gingivitis (40). Corbet found no significant differences in PI in outpatients with gingival inflammation; however, there was a significant difference in gingival BI or bleeding rates for 90 days between the CHX and experimental groups (41). In other studies, Zanatta et al. discovered little anti-tooth plaques and anti-gingivitis impact of CHX mouthwash on earlier tooth plaque shielded areas, as well as the benefit of excluding formed dental biofilm prior to CHX use (42). After four weeks, there were significant differences in gingival inflammation reduction between the CHX and CPC mouthwashes in the study. Earlier research by Türkoğlu showed that using $\mathrm{CHX}$ mouth rinse as a supplement to normal plaque prevention could be beneficial in the treatment of plaque-related gingival tissue inflammation (43). Moreover, Becerik indicated CHX could be useful in reducing the subgingival total bacteria count, especially in posterior teeth (44). The data indicated the major obvious effectiveness of CPC mouth rinses on specimens of supra-gingival dental plaque obtained from human cases and established prior clinical examinations manifesting notable impacts of CPC on tooth plaques, including the inflammation of the gingiva (45-48).

CPC is a quaternary ammonium compound that is utilized in a wide range of antiseptic mouth rinse products containing $0.07 \%$ alcohol. Daily cleaning and washing with CPC significantly reduce clinical documentation of gingivitis. In certain circumstances, Kiszely et al. (49) used it as a supplement to normal oral health plans. The usage of CPC appeared to result in a significant decrease in tooth plaque rates. According to the PI's estimation, this was for the earlier findings of multiple prior research (49-51). When used in conjunction with normal and routine oral health practices, CPC develops bleeding levels (a sign of gingival health). Reliable results are those that correspond to previous investigations when $\mathrm{CPC}$ was utilized $(49,52)$. Ciancio et al. stated that there was no improvement in 
bleeding scores in the test group, which included dental cleaning and brushing. The side effects of quaternary ammonium composites include achromatism, a variety of flavors, and a burning sensation (53). Lobene (1979) studied the effectiveness of CPC on gingivitis and dental plaque for 21 days and found it to be between 1:1000 and 1:2000 (54). The participants cleaned and brushed their teeth as usual, but they also rinsed with $20 \mathrm{ml}$ of CPC for 20 seconds twice a day for 21 days. Witt et al. (2005) (55) investigated the agonist for bacterial and dental plaque qualities of a novel, non-alcoholic, oral-rinsed with CPC. They determined that the CPC mouthwash showed a broad spectrum of anti-microorganism processes. Allen et al. discovered that after cleaning and rinsing with $15 \mathrm{ml}$ of a $0.05 \%$ CPC mouth rinse for 60 seconds, the CPC group had $28 \%$ less plaque biofilm of the tooth, a $63 \%$ decrease in tooth plaque accumulation, $24 \%$ more moderate gingiva inflammation, and $67 \%$ less gingival bleeding when compared to the control group (56). In a study conducted by Mankodi et al. (49), patients used $20 \mathrm{ml}$ of a nonalcohol 0.07 percent CPC rinse for 30\%, and the CPC group had 16\% less plaque and 33\% less gingival bleeding than the control group (49). Finally, Stookey et al. evaluated two alcohol-free mouthwashes, one containing $0.075 \%$ $\mathrm{CPC}$ and the other containing $0.1 \%$ CPC (48). Patients used $20 \mathrm{ml}$ in 30 seconds. Drops in plaque and gingivitis were $17 \%$ and $23 \%$ for the $0.075 \%$ CPC group, respectively, and $19 \%$ and $20 \%$ for the $0.1 \%$ CPC group. However, despite differences in items, these investigations revealed that correct CPC compounds have significant anti-plaque and gingivitis impacts (57). Rioboo et al. discovered that the evaluated toothpaste and oral rinse with $0.05 \% \mathrm{CPC}$ as adjuncts to oral cleanliness and health had insufficient benefits in terms of reducing dental plaque formation and having no effect on gingival inflammation (58). According to Zimmer et al., there was no statistically significant difference among those without alcohol and the alcohol-comprising preliminary washes (59). Achromatism is one of the numerous negative outcomes that have been published. Clinical observations have revealed significant changes in the specific stain trends that follow each cycle of CHX washing and cleaning $(60,61)$. The present study's findings revealed that there was tooth discoloration in both groups, although there were no statistically significant extrinsic stained teeth during the examination.

During the trial, people in the CHX and CPC groups had no statistically significant extrinsic tooth discoloration, according to Charles et al. (62). Furthermore, CPC oral-rinsed was found to have fewer side effects than CHX mouthwash. Blenman et al. discovered less staining with CPC mouthwash compared to CHX mouthwash, and they stated that patients can use longer-term rinsing time with CPC mouth-rinse because there will be no burning sensation and bitter flavor because it contains no alcohol (63). Quirynen et al., defined the CHX and CPC formalization while comparing it with alternative CHX-alcohol compounds, particularly for the taste and flavor of the yield, but less efficient for the discoloring of the teeth region also tongue (12). The findings of Papaioannou et al. (17) research on discoloring or staining of the tooth cover were incorporated into the current study (61). The present study's findings were consistent with those of Jose et al. on $0.2 \%$ CHX mouth rinse including alcohol and nonalcohol mouthwash (65), L. Borrajo et al. on $0.12 \%$ CHX, $0.05 \%$ sodium fluoride, $11 \%$ ethanol, and the similar nonalcoholic mouth rinse (66). According to Charles et al., $0.12 \%$ CHX oral rinse significantly increased calculus and the presence of discoloration or stains when compared to EO oral-rinse, and the test group (62). Sreenivasanet et al. found that the CPC mouthwash had significantly better antibacterial performance ( $90 \%$ killing), while the CHX mouthwash had the maximum efficiency. Mouth rinses containing $0.05 \% \mathrm{CPC}$ in an alcohol or alcohol-free base exhibited broad-spectrum of antibacterial effect on supragingival plaque biofilm when compared to a control mouthwash that did not contain CPC (67). Pandit et al. proposed that CPC medications have strong anti-S. Mutant's dental biofilm capacity (68). Latimer et al. described the use of CPC and sodium fluoride in mouthwash to prevent the bacteria and protect the mouth and dental enamel (69). According to Rösing et al., a mouthwash containing CPC and zinc lactate has significant anti-plaque and anti-gingivitis effects when compared to affirmative and adverse control oral rinses (70). However, the primary constraint of the preliminary examination is a lack of specimen volume. The investigation began with 38 subjects; four of the participants were dismissed for unknown reasons. Microbiological examinations are also required on a large scale and over a long period of time to establish the effectiveness and protection of CPC without alcohol on the health of gingival or periodontal tissues as a comparison to other anti-dental plaque and anti-inflammation agents on the gingiva. Therefore, based on the findings of many studies, including those of the present research, it can be determined which CPC mouth rinses without alcohol can be used as a substitute for CHX mouthwash, which could be used for a while. The present study's findings indicate that CPC without alcohol is helpful in decreasing clinical periodontal markers; however, we believe that further research is required to back up this finding with strong data.

\section{Conclusions}

The study discovered that using a therapeutic CPC mouth rinse twice a day helps to control plaque and gingivitis or periodontitis in addition to mechanical plaque prevention, but not as much as AFCHX oral-rinse. The number of 
adverse reactions (taste alterations and tooth discoloration) were associated with chlorhexidine treatment in the CHX group. Thus, similar to the findings of the current study and other studies, it can be expected that CPC oral rinses without alcohol can be another CHX mouthwash that could be used for a period of time.

\section{Acknowledgments:}

The authors received no financial support for their investigation. The authors would like to express their gratitude to their staff in the Department of Periodontics, Dental School, Islamic Azad University of Medical Sciences, Tehran, Iran.

\section{Conflict of Interest:}

There is no conflict of interest to be declared.

\section{Authors' contributions:}

All authors contributed to this project and article equally. All authors read and approved the final manuscript.

\section{References:}

1) Potempa J, Banbula A, Travis J. Role of bacterial proteinases in matrix destruction and modulation of host responses. Periodontol 2000, 2000: Oct 24: 153-92. doi: 10.1034/j.1600-0757.2000.2240108.x, PMid: 11276866

2) Bartold PM, Van Dyke TE. Periodontitis: a host-mediated disruption of microbial homeostasis. Unlearning learned concepts. Periodontol 2000. 2013 Jun; 62(1):203-17. doi: 10.1111/j.1600-0757.2012.00450.x, PMid: 23574467, PMCid: PMC3692012

3) Mandel ID. Dental plaque: nature, formation and effects. J Periodontology, 1966; 37:537-567. doi: 10.1902/jop.1966.37.5.357

4) Theilade E, Wright WH, Jensen SB, Loe H. Experimental gingivitis in man. II. A longitudinal clinical and bacteriological investigation. J Periodontal Research, 1966; 1:1-13. doi: 10.1111/j.16000765.1966.tb01842.x, PMid: 4224181

5) Warren PR, Landmann H, Chater BV. Electric toothbrush use. Attitudes and experience among dental practitioners in Germany. American J Dentistry, 1998; 11:S3-6.

6) Teles RP, Teles FR. Antimicrobial agents used in the control of periodontal biofilms: effective adjuncts to mechanical plaque control? Braz Oral Res. 2009; 23 Suppl 1:39-48. doi: 10.1590/S180683242009000500007, PMid: 19838557

7) Paraskevas S, Van der Weijden GA. A review of the effects of stannous fluoride on gingivitis. J Clin Periodontol 2006; 33: 1-13. doi: 10.1111/j.1600-051X.2005.00860.x, PMid: 16367849

8) Barnett ML. The role of therapeutic antimicrobial mouth rinses in clinical practice. Control of supragingival plaque and gingivitis. J Am Dent Assoc 2003; 134: 699-701.

9) Kumar S, Patel S, Tadakamadla J, Tibdewal H, Duraiswamy P, Kulkarni S. Effectiveness of a mouthrinse containing active ingredients in addition to chlorhexidine and triclosan compared with chlorhexidine and triclosan rinses on plaque, gingivitis, supragingival calculus and extrinsic staining. Int J Dent Hyg. 2013; 11(1):35-40. doi: 10.1111/j.1601-5037.2012.00560.x, PMid: 22672130

10) Bhate $\mathrm{D}$, Jain $\mathrm{S}$, Kale R, Muglikar S. The comparative effects of $0.12 \%$ chlorhexidine and herbal oral rinse on dental plaque-induced gingivitis: A randomized clinical trial. Journal of Indian Society of Periodontology. 2015; 19(4):393-5. doi: 10.4103/0972-124X.153478, PMid: 26392686, PMCid: PMC4555795

11) Leyes Borrajo JL, Garcia VL, Lopez CG, Rodriguez-Nunez I, Garcia FM, Gallas TM. Efficacy of chlorhexidine mouthrinses with and without alcohol: a clinical study. J Periodontol. 2002; 73(3):317-21. doi: 10.1902/jop.2002.73.3.317, PMid: 11924590

12) Quirynen M, Avontroodt P, Peeters W, Pauwels M, Coucke W, van Steenberghe D. Effect of different chlorhexidine formulations in mouthrinses on de novo plaque formation. Journal of clinical periodontology. 2001; 28(12):1127-36. doi: 10.1034/j.1600-051X.2001.281207.x, PMid: 11737510

13) Feres M, Figueiredo LC, Faveri M, Stewart B, Vizio W. The effectiveness of a preprocedural mouthrinse containing cetylpyridinium chloride in reducing bacteria in the dental office. J Am Dent Assoc. 2010; 141(4):415-22. doi: 10.14219/jada.archive.2010.0193, PMid: 20354090

14) Gupta G, Mitra D, Ashok KP, Gupta A, Soni S, Ahmed S et al. Efficacy of preprocedural mouth rinsing in reducing aerosol contamination produced by ultrasonic scaler: a pilot study. J Periodontol. 2014; 85(4):5628. doi: 10.1902/jop.2013.120616, PMid: 23855840 
15) Leggat PA, Kedjarune U. Bacterial aerosols in the dental clinic: a review. Int Dent J. 2001; 51(1):39-44. doi: 10.1002/j.1875-595X.2001.tb00816.x, PMid: 11326448

16) Logothetis DD, Martinez-Welles JM. Reducing bacterial aerosol contamination with a chlorhexidine gluconate pre-rinse. J Am Dent Assoc. 1995; 126(12):1634-9. doi: 10.14219/jada.archive.1995.0111, PMid: 7499664

17) Jones CG. Chlorhexidine: is it still the gold standard? Periodontol. 2000. 1997; 15(1):55-62. doi: 10.1111/j.1600-0757.1997.tb00105.x, PMid: 9643233

18) Thomas E. Efficacy of two commonly available mouth rinses used as preprocedural rinses in children. J Indian Soc Pedod Prev Dent. 2011; 29(2):113-6. doi: 10.4103/0970-4388.84682, PMid: 21911948

19) Varoni E, Tarce M, Lodi G, Carrassi A. Chlorhexidine (CHX) in dentistry: state of the art. Minerva Stomatol. 2012; 61(9):399-419.

20) Boneta AE, Aguilar MM, Romeu FL et al. Comparative investigation of the efficacy of triclosan/copolymer/sodium fluoride and stannous fluoride/sodium hexametaphosphate/zinc lactate dentifrices for the control of established supragingival plaque and gingivitis in a six-month clinical study. $\mathrm{J}$ Clin Dent 2010; 21 (4): 117-123.

21) Costa X, Laguna E, Herrera $D$ et al. Efficacy of a new mouth rinse formulation based on $0.07 \%$ cetylpyridinium chloride in the control of plaque and gingivitis: a 6-month randomized clinical trial. J Clin Periodontol 2013; 40 (11): 1007-1015. doi: 10.1111/jcpe.12158, PMid: 24024983

22) Fine DH. Chemical agents to prevent and regulate plaque development. Periodontol 2000 1995; 8: 87-107. doi: 10.1111/j.1600-0757.1995.tb00047.x, PMid: 9567948

23) Teles RP, Teles FR. Antimicrobial agents used in the control of periodontal biofilms: the effective adjuncts to mechanical plaque control? Braz Oral Res 2009; 23 (Suppl 1): 39-48. doi: 10.1590/S180683242009000500007, PMid: 19838557

24) Haps S, Slot DE, Berchier CE et al. The effect of cetylpyridinium chloride-containing mouth rinses as adjuncts to tooth brushing on plaque and parameters of gingival inflammation: a systematic review. Int $\mathbf{J}$ Dent Hyg 2008; 6 (4): 290-303. doi: 10.1111/j.1601-5037.2008.00344.x, PMid: 19138180

25) Gunsolley JC. Clinical efficacy of antimicrobial mouthrinses. J Dent 2010; 38 (Suppl 1): S6-S10. doi: 10.1016/S0300-5712(10)70004-X

26) Serrano J, Escribano M, Roldán S, Martín C, Herrera D. Efficacy of adjunctive anti-plaque chemical agents in managing gingivitis: a systematic review and meta-analysis. J Clin Periodontol 2015; 42 Suppl 16:S10638. doi: $10.1111 /$ jcpe.12331, PMid: 25495592

27) Haps S, Slot DE, Berchier CE, Van der Weijden GA. The effect of cetylpyridinium chloride-containing mouth rinses as adjuncts to toothbrushing on plaque and parameters of gingival inflammation: a systematic review. Int J Dent Hyg 2008; 6:290-303. doi: 10.1111/j.1601-5037.2008.00344.x, PMid: 19138180

28) Gunsolley JC. Clinical efficacy of antimicrobial mouthrinses. J Dent 2010; 38 Suppl 1:S6-10. doi: 10.1016/S0300-5712(10)70004-X

29) Quirynen M, Soers C, Desnyder M, Dekeyser C, Pauwels M, van Steenberghe D. A $0.05 \%$ cetyl pyridinium chloride $/ 0.05 \%$ chlorhexidine mouth rinse during maintenance phase after initial periodontal therapy. J Clin Periodontol. 2005 Apr; 32(4):390-400. doi: 10.1111/j.1600-051X.2005.00685.x, PMid: 15811057

30) Turesky S, Gilmore ND, Glickman I. Reduced plaque formation by the chloromethyl analogue of victamine C. J Periodontol. 1970 Jan; 41(1):41-43. doi: 10.1902/jop.1970.41.1.41, PMid: 5264376

31) Timothy J. O'Leary. Robert B. Drake. James E. Naylor. The Plaque Control Record. Journal of Periodontology .January 1972; 43(1): 38-40. doi: 10.1902/jop.1972.43.1.38, PMid: 4500182

32) Ainamo J, Bay I. Problems and proposals for recording gingivitis and plaque. Int Dent J 1975; 25:229 35.

33) Carter HG, Barnes GP. The Gingival Bleeding Index. J Periodontol. 1974 Nov; 45(11):801-5. doi: 10.1902/jop.1974.45.11.801, PMid: 4547795

34) Lobene RR. Effect of dentifrices on tooth stains with controlled brushing. J Am Dent Assoc. 1968; 77:84955. doi: 10.14219/jada.archive.1968.0298, PMid: 5244497

35) Lopez-Jornet P, Plana-Ramon E, Leston JS, Pons-Fuster A. Short term side effects of $0.2 \%$ alcohol-free chlorhexidine mouthrinse in geriatric patients: a randomized, double blind, placebo- controlled study.Gerodontology. 2012; 29(4):292-98. doi: 10.1111/j.1741-2358.2012.00671.x, PMid: 22486193

36) Jones CG. Chlorhexidine: is it still the gold standard? Periodontol 2000. 1997; 15:55-62. doi: 10.1111/j.1600-0757.1997.tb00105.x, PMid: 9643233 
37) Van Strydonck DA, Slot DE, Van der Velden U, Van der Weijden F. Effect of a chlorhexidine mouthrinse on plaque, gingival inflammation and staining in gingivitis patients: a systematic review. J Clin Periodontol.2012; 39:1042-55. doi: 10.1111/j.1600-051X.2012.01883.x, PMid: 22957711

38) Sanz M, Vallcorba N, Fabregues S, Müller I, Herkströter F. The effect of a dentifrice containing chlorhexidine and zinc on plaque, gingivitis, calculus and tooth staining. J Clin Periodontol. 1994; 21:4317. doi: 10.1111/j.1600-051X.1994.tb00741.x, PMid: 8089246

39) La Vecchia C: Mouthwash and oral cancer risk: An update. Oral Oncol. 2009, 45: 198-200. doi: 10.1016/j.oraloncology.2008.08.012, PMid: 18952488

40) Brownstein CN, Briggs SD, Schweitzer KL, Briner WW, Kornman KS. Irrigation with chlorhexidine to resolve naturally occurring gingivitis. A methodologic study. J Clin Periodontol. 1990; 17:588-593. doi: 10.1111/j.1600-051X.1990.tb01110.x, PMid: 2212090

41) Corbet EF, Tam JO, Zee KY, Wong MC, Lo EC, Mombelli AW, et al. Therapeutic effects of supervised chlorhexidine mouthrinses on untreated gingivitis. Oral Dis. 1997; 3(1):9-18. doi: 10.1111/j.16010825.1997.tb00003.x, PMid: 9456641

42) Zanatta FB, Antoniazzi RP, Rösing CK. The effect of $0.12 \%$ chlorhexidine gluconate rinsing on previously plaque-free and plaque- covered surfaces: a randomized, controlled clinical trial. J Periodontol. 2007; 78:2127-2134. doi: 10.1902/jop.2007.070090, PMid: 17970679

43) Türkoğlu O, Becerik S, Emingil G, Kütükçüler N, Baylas H, Atilla G. The effect of adjunctive chlorhexidine mouthrinse on clinical parameters and gingival crevicular fluid cytokine levels in untreated plaque-associated gingivitis. Inflamm Res. 2009; 58:277-283. doi: 10.1007/s00011-008-8129-z, PMid: 19184351

44) Becerik S, Türkoğlu O, Emingil G, Vural C, Ozdemir G, Atilla G. Antimicrobial effect of adjunctive use of chlorhexidine mouthrinse in untreated gingivitis: a randomized, placebo-controlled study. APMIS. 2011 Jun; 119(6):364-72. doi: 10.1111/j.1600-0463.2011.02741.x, PMid: 21569094

45) 45.Allen, D.R., Davies, R., Bradshaw, B., Ellwood, R., Simone, A. J., Robinson, R., Mukerjee, C., Petrone, M.E. et al. Efficacy of a mouthrinse containing $0.05 \%$ cetylpyridinium chloride for the control of plaque and gingivitis: a 6- month clinical study in adults. Compend Contin Educ Dent 1998; 19 (2 Suppl.), $20-26$.

46) Hernandez-Cott, P.L., Boneta, A.E., Stewart, B., DeVizio, W. and Proskin, H.M. A clinical investigation of the efficacy of a commercial mouthrinse containing $0.05 \%$ cetylpyridinium chloride in reducing dental plaque. J Clin Dent 2009; 20, 39-44.

47) 47.Lotufo, R., Calil, C.M., Feng, H.S., Sekiguchi, R.T., Stewart, B., DeVizio, W. and Proskin, H.M. (2009) Clinical investigation of the efficacy of a commercial mouthrinse containing $0.05 \%$ cetylpyridinium chloride in preventing dental plaque. J Clin Dent 2009; 20, 50-54

48) Silva, M.F., Santos, N.B., Stewart, B., DeVizio, W. and Proskin, H.M. A clinical investigation of the efficacy of a commercial mouthrinse containing $0.05 \%$ cetylpyridinium chloride to control established dental plaque and gingivitis. J Clin Dent 2009; 20, 55-61

49) Kiszely A. Comparison of the effects of cetylpyridinium chloride with an essential oil mouthrinse on dental plaque and gingivitis - a six month randomized control trial. J. Clin. Periodontol. 2007; 34:658-667. doi: 10.1111/j.1600-051X.2007.01103.x, PMid: 17635245

50) Holbeche J.D., Ruljancich M.K., Reade P.C. A clinical trial of the efficacy of a cetylpyridinium chloride mouthwash: TEMPeffect on plaque accumulation and gingival condition. Aust. Dent. J. 1975; 6:397-404. doi: 10.1111/j.1834-7819.1975.tb04390.x, PMid: 1062978

51) 51.Mankodi S., Bauroth K., Witt J.J., Bsoul S., He T., Gibb R., Dunavent J., Hamilton A. A six month clinical trial to study teh TEMPeffects of a cetylpyridinium chloride mouthrinse on gingivitis and plaque. Am. J. Dent. 2005; 18:9A-14A.

52) 52.Roberts W.R., Addy M. Comparison of the in vivo and in vitro antibacterial properties of antiseptic mouthrinse containing chlorhexidine, alexidine, cetylpyridinium chloride and hexitidine. Relevance to mode of action. J. Clin. Periodontol. 1981; 8(4):295-310. doi: 10.1111/j.1600-051X.1981.tb02040.x, PMid: 6947993

53) Ciancio S.G. Agents for the management of plaque and gingivitis. J. Dent. Res. 1992; 71:1450-1454. doi: 10.1177/00220345920710071701, PMid: 1629462

54) Lobene R.R. Clinical studies of plaque control agents: an overview. J. Dent. Res. 1979; 58 (12):2381-2388. doi: 10.1177/00220345790580120902, PMid: 117032

55) Witt J., Ramji N., Gibb R., Dunavent J., Flood J., Barnes J. Antibacterial and antiplaque effects of a novel, alcohol free oral rinse with cetylpyridinium chloride. J. Contemp. Dent. Pract. 2005; 6:15. doi: 10.5005/jcdp-6-1-1, PMid: 15719071 
56) 56.Allen, D.R., Davies, R., Bradshaw, B., Ellwood, R., Simone, A. J., Robinson, R., Mukerjee, C., Petrone, M.E. et al. (1998) Efficacy of a mouthrinse containing $0.05 \%$ cetylpyridinium chloride for the control of plaque and gingivitis: a 6- month clinical study in adults. Compend Contin Educ Dent 19 (2 Suppl.), 20-26.

57) 57.Stookey GK, Beiswanger B, Mau M, Isaacs RL, Witt JJ, Gibb R. A 6- month clinical study assessing the safety and efficacy of two cetylpyridinium chloride mouthrinses. Am J Dent 2005; 18 (Sp Is A):24A-28A.

58) Rioboo M, García V, Serrano J et al. Clinical and microbiological efficacy of an antimicrobial mouth rinse containing $0.05 \%$ cetylpyridinium chloride in patients with gingivitis. Int J Dent Hyg 2012; 10 (2): 98-106. doi: 10.1111/j.1601-5037.2011.00523.x, PMid: 2183125

59) 59..Zimmer S, Korte P, Verde P, Ohmann C, Naumova E, Jordan RA. Randomized controlled trial on teh efficacy of new alcohol-free chlorhexidine mouthrinses after 8 weeks. Int J Dent Hyg. 2015 May; 13(2):110-6. doi: 10.1111/idh.12111, PMid: 25382448

60) Ellingsen JE, Rolla G, Eriksen HM. Extrinsic dental stain caused by chlorhexidine and other denaturing agents. J Clin Periodontal. 1982; 9(4):317-322. doi: 10.1111/j.1600-051X.1982.tb02098.x, PMid: 6821208

61) Flötra L. Different modes of chlorhexidine application and related local side effects. J Periodontal Res Suppl. 1973; 12(3):41-44. doi: 10.1111/j.1600-0765.1973.tb02162.x, PMid: 4269597

62) Charles $\mathrm{CH}$, Mostler KM, Bartels LL, Mankodi SM. Comparative antiplaque and antigingivitis effectiveness of a chlorhexidine and an essential oil mouthrinse: 6-month clinical trial. Journal of clinical periodontology. 2004; 31(10):878-84. doi: 10.1111/j.1600-051X.2004.00578.x, PMid: 15367192

63) Blenman TV, Morrison KL, Tsau GJ, Medina AL, Gerlach RW. Practice implications with an alcohol-free, 0.07\% cetylpyridinium chloride mouthrinse. Am J Dent. 2005; 18 Spec No: 29A-34.

64) Papaioannou W, Vassilopoulos S, Vrotsos I, Margaritis V, Panis V. A comparison of a new alcohol-free $0.2 \%$ chlorhexidine oral rinse to an established $0.2 \%$ chlorhexidine rinse with alcohol for the control of dental plaque accumulation. Int J Dent Hyg. 2015. doi: 10.1111/idh.12182, PMid: 26449740

65) Jose A, Butler A, Payne D, Maclure R, Rimmer P, Bosma ML. A randomised clinical study to evaluate the efficacy of alcohol-free or alcohol-containing mouthrinses with chlorhexidine on gingival bleeding. British dental journal. 2015; 219(3):125-30. doi: 10.1038/sj.bdj.2015.592, PMid: 26271869, PMCid: PMC4648057

66) Leyes Borrajo JL, Garcia VL, Lopez CG, Rodriguez-Nunez I, Garcia FM, Gallas TM. Efficacy of chlorhexidine mouthrinses with and without alcohol: a clinical study. J Periodontol. 2002; 73(3):317-21. doi: 10.1902/jop.2002.73.3.317, PMid: 11924590

67) Sreenivasan PK, Haraszthy VI, Zambon JJ. Antimicrobial efficacy of $0.05 \%$ cetylpyridinium chloride mouthrinses. Lett Appl Microbiol 2013; 56 (1): 14-20. doi: 10.1111/lam.12008, PMid: 23039819

68) Pandit S, Cai JN, Jung JE, Lee YS, Jeon JG. Effect of brief cetylpyridinium chloride treatments during early and mature cariogenic biofilm formation. Oral Dis. 2015; 21(5):565-71. doi: 10.1111/odi.12312, PMid: 25600577

69) Latimer J, Munday JL, Buzza KM et al. Antibacterial and anti-biofilm activity of mouth rinses containing cetylpyridinium chloride and sodium fluoride. BMC Microbiol 2015; 15: 169. doi: 10.1186/s12866-0150501-x, PMid: 26293609, PMCid: PMC4546200

70) Rösing CK, Cavagni J, Gaio EJ, Muniz FWMG, Ranzan N, Oballe HJR, Friedrich SA, Severo RM, Stewart B, Zhang YP. Efficacy of two mouthwashes with cetylpyridinium chloride: a controlled randomized clinical trial. Braz Oral Res. 2017 Jul 3; 31:e47. doi: 10.1590/1807-3107bor-2017.vol31.0047, PMid: 28678966 